\title{
Improving daytime detection of deer for surveillance and management
}

\author{
Thomas W. Logan ${ }^{1} \cdot$ Adham Ashton-Butt ${ }^{1} \cdot$ Alastair I. Ward $^{1}$ (D) \\ Received: 1 April 2019 /Revised: 29 July 2019 / Accepted: 26 August 2019/Published online: 14 October 2019 \\ (C) The Author(s) 2019
}

\begin{abstract}
Maximising the detection of a target species reduces the uncertainty of survey results and can improve management outcomes. Deer (Cervidae) populations are managed worldwide due to their impacts on anthropocentric interests. In the UK, deer can only lawfully be shot during the daytime, from $1 \mathrm{~h}$ before sunrise to $1 \mathrm{~h}$ after sunset, when deer activity is at its lowest. We evaluated performance of a thermal imager relative to binoculars for their ability to detect deer during the daytime and at twilight ( $1 \mathrm{~h}$ either side of dawn and dusk). Transect surveys on Thorne Moors, UK, revealed that more roe and red deer were observed using a thermal imager than when using binoculars. More deer in much larger groups were observed at twilight than during the other daylight hours. Variation in animal detectability at different times of the day must be considered during wildlife surveys if their outputs are to be as accurate and precise as possible. The results support the continued focus of deer culling efforts during the hours of twilight. They also highlight the potential utility of thermal imagers for maximising detection probability at twilight.
\end{abstract}

Keywords Cervus elaphus $\cdot$ Capreolus capreolus $\cdot$ Binoculars $\cdot$ Detection $\cdot$ Survey $\cdot$ Thermal imager

\section{Introduction}

Accurate estimates of animal occupancy and population size depend on high detection probability (MacKenzie et al. 2002; Field et al. 2007; Petrovan et al. 2011), yet many wildlife surveys suffer low detection rates (Legg and Nagy 2006), leading to elevated uncertainty (Nichols 2019). Detection can be impacted by animal behaviour; animals that are crepuscular or nocturnal can be more difficult to detect than those active during the daytime (Jiang et al. 2008). Consequently, technology, including artificial light, night vision, and thermal imagery, has been employed to improve the detection of wild animals at night, (Gill et al. 1997; Allison and Destefano 2006), resulting in significant improvements in the accuracy and precision of population estimates derived from field surveys (Smart et al. 2004). However, daytime surveys have been

Electronic supplementary material The online version of this article (https://doi.org/10.1007/s10344-019-1318-y) contains supplementary material, which is available to authorized users.

Alastair I. Ward

a.i.ward@hull.ac.uk

1 Department of Biological and Marine Sciences, University of Hull, Hull HU6 7RX, UK used (Fragoso et al. 2016) and even advocated by some researchers (Vincent et al. 1991; Trenkel et al. 1997), and in our experience, such surveys are often preferred by land managers. Nevertheless, the relative performance of technologically supported surveys during the hours of daylight and the hours of darkness has not, to our knowledge, been evaluated.

Much of the focus of surveys for wild deer (Cervidae) has been to support their management (Smart et al. 2004). Deer populations are often culled to control their impacts on anthropocentric interests (Putman and Moore 1998). Thermal imagery has been used extensively to survey wild deer at night (Gill et al. 1997; Focardi et al. 2001; Wäber et al. 2013) since hunted populations tend to be crepuscular or nocturnal (Beier and McCullough 1990; Meng et al. 2002). However, its use for management by most hunters has only recently become feasible due to declining costs and improving functionality. Nevertheless, costs of hand-held thermal imagers suitable for hunting are currently comparable to the costs of high-end rifle telescopic sights, so substantial enhancement of deer detection, leading to improved culling efficiency, is required to justify the investment.

Across much of Europe deer may be hunted at night (Putman et al. 2011a), but in the UK, primary legislation limits their lawful shooting to the daytime only. The Deer Act 1991 requires that no deer may be shot between $1 \mathrm{~h}$ after sunset until $1 \mathrm{~h}$ before sunrise. To control or reverse the continuing growth and spread of British 
deer populations (Ward 2005; Mathews et al. 2018) and hence their impacts on anthropocentric interests, deer managers may benefit from enhanced deer detection rates during the daytime.

We sought to identify times of day when deer detection rates were at their highest and compared the daytime deer detection performance of a thermal imager with the more traditional use of binoculars so that researchers and managers alike can make informed choices about technological aids and times of day when planning deer surveys.

\section{Materials and methods}

Transect surveys for red deer (Cervus elaphus) and roe deer (Capreolus capreolus) took place on Thorne Moors, UK (53.636654, -0.898764$)$ from 21 February 2018 to 14 March 2018 between the hours of 05.00 and 19.00. The site is a National Nature Reserve of approximately $19 \mathrm{~km}^{2}$, managed for its nationally and seasonally important populations of water birds, but with significant areas of scrub and deciduous woodland.

Transects were approximately $500 \mathrm{~m}$ in length, with at least $1 \mathrm{~km}$ between the end of one and the start of the next to avoid double-counting deer fleeing between transects and hence to avoid pseudo-replication (Focardi et al. 2002). Each transect was surveyed on foot eight times; twice with binoculars $(10 \times$
50 magnification, SkyGenius, Massachusetts, USA) and twice with the thermal imager (FLIR BHS-XR, FLIR Systems, Inc., OR, USA) during each of the hours of daylight (between sunrise and sunset) and at twilight (the hour before sunrise and after sunset). The thermal imager was chosen since it is an older model with a lower specification than many more recent products, but which nevertheless had a sensitivity of $30 \mathrm{mK}$. The choice to start a survey with binoculars or thermal imager was decided by a coin toss, with the subsequent survey of the same transect conducted with the other detection method. A period of at least $24 \mathrm{~h}$ was maintained between surveys of the same transect. Data collected were species, number of groups detected, number of animals per group, and time of day.

To compare the detection of deer between detection methods ( $1=$ binoculars and $2=$ thermal imager) and time of day (either as a covariate: the absolute number of hours from 07.00 or the signed number of hours from 07.00 , or as a binary factor: $1=$ daylight and $2=$ twilight), general linear mixed models (GLMMs) with a Poisson distribution and a log link function were fitted to the count data (Zuur et al. 2007) using R package "Ime4" (Bates et al. 2014). Separate models were built for each deer species when detections were summarised as the number of deer groups per transect and number of individuals per transect. 'Transect' and 'date sampled' were fitted as random effects and 'detection method' and 'time of day' as fixed effects, including
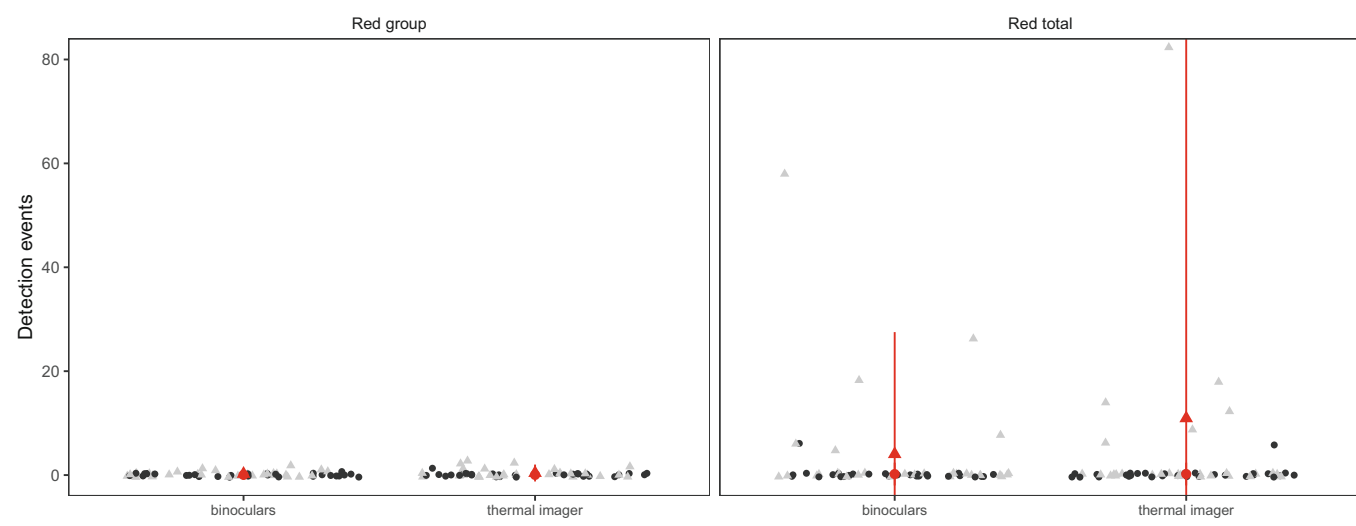

Time.of.day

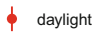

4 twilight
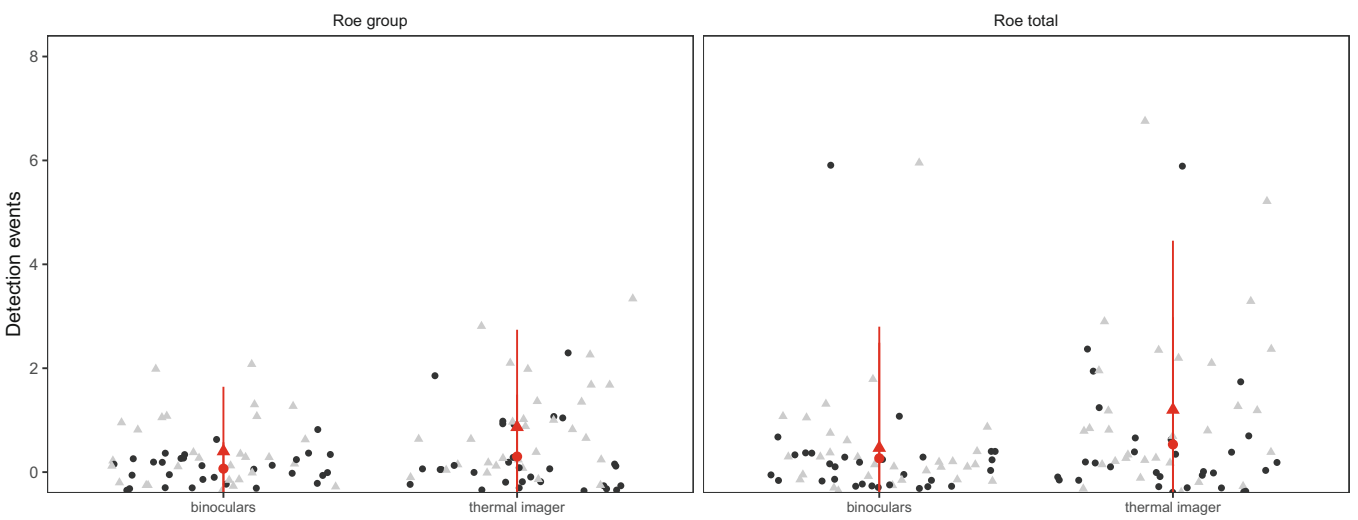

Time.of.day

daylight

4 twilight

Fig. 1 Number of deer detection events per transect, for groups of red and roe deer and total individuals, using binoculars and thermal imaging cameras. Mean values are in red with bars showing the standard deviation 
an interaction effect. Model fit was evaluated by visual examination of residuals versus fitted values, which is one of many accepted quality assurance procedures (Zuur et al. 2007; Harrison et al. 2018). All statistical analysis was performed in R 3.4.4 (R Core Team 2018).

\section{Results}

In total, 63 roe deer and 463 red deer were observed in groups of $1-6($ median $=1)$ and $5-187($ median $=12)$ respectively at a mean of 1.64 roe deer and 7.68 red deer per $\mathrm{km}$ surveyed. Air temperature varied little during the study, from -0.4 to $7.7^{\circ} \mathrm{C}$. Sunrise occurred at approximately 07.00 and sunset at approximately 17.30.

In no model was time of day, when entered as a covariate, associated with the number of deer detected $(P<0.001$ in all cases), so it was included as a binary variable only during subsequent models. However, the total number of deer and number of deer groups detected was considerably higher during twilight than during the hours of daylight for both species (Fig. 1 and Table 1) but was of marginal significance $(p=$ 0.069 ) for red deer groups. Time of day and detection method had an interaction effect, with number of deer and number of groups detected higher at twilight using the thermal imager than using binoculars, apart from detection of red deer groups, which was not discernibly different, whether using binoculars or thermal imager. More roe deer were detected with the thermal imager than with binoculars during daylight hours, but this result did not extend to red deer (Table 1).

\section{Discussion}

More deer were observed using the thermal imager than with binoculars, especially at twilight. This is unsurprising, since this technology was developed to enhance detection rates of heat-emitting objects. However, while thermal imagery has traditionally been used to survey deer at night (Gill et al. 1997; Wäber et al. 2013), we have demonstrated that deer may be more easily detected during the daytime, particularly around dawn and dusk, but also that roe deer may be more easily detected during the hours of daylight.

Higher detection rates at twilight were somewhat surprising because deer are actively culled on farmland around the study site at this time, but there is currently no culling of deer on the nature reserve. It is nevertheless consistent with the crepuscular/nocturnal behaviours expressed by deer in hunted populations, and those exposed to high predation pressure (Hewison, et al. 2001; Benhaiem, et al. 2008; Jiang et al. 2008).

Variation in gregarious behaviours across different times of the day by red deer, as observed in Scotland

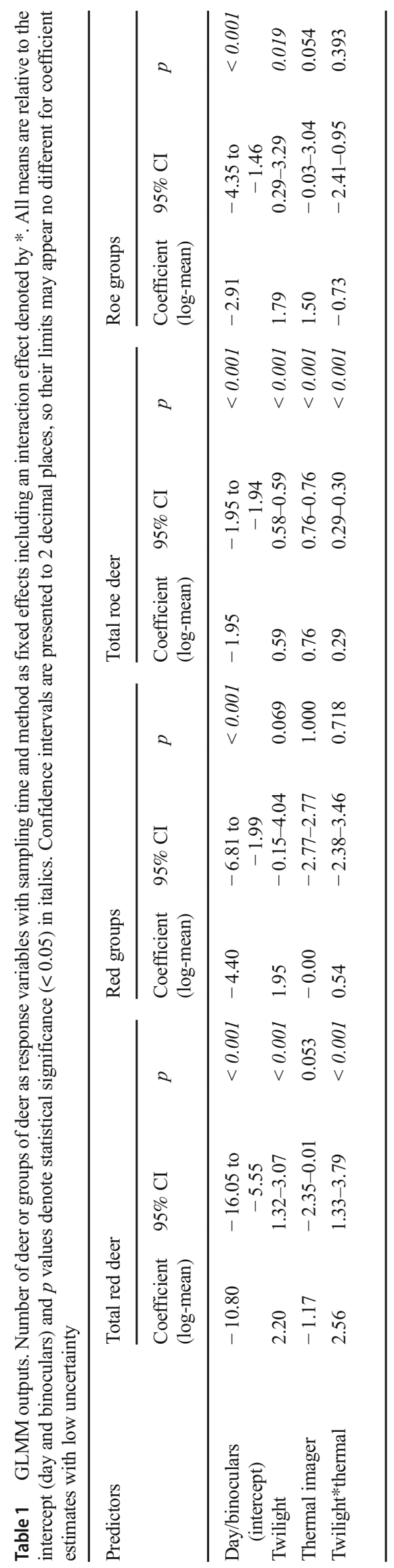


(Mitchell et al. 1977) caused the lack of difference in the number of red deer groups detected despite the higher number of individual deer observed at twilight. Red deer simply formed fewer, larger groups at twilight. Differences in behaviour and hence detectability at different times of day have important implications for wildlife surveys since high detectability is required for accurate estimates of a species' occurrence and population size (MacKenzie et al. 2002; Nichols 2019). Moreover, users of the results of wildlife surveys should also consider the consequences of these sources of variability in detection. Increasingly, researchers seeking to estimate wildlife distribution and abundance patterns use third party data, often produced during surveys undertaken by amateur surveyors (Horns et al. 2018; Massimino et al. 2018). Surveys that are not designed to account for, or take advantage of, variation in detectability within and between species risk mis-estimating species occurrence and abundance, with errors being perpetuated or amplified in modelled outputs (Legg and Nagy 2006).

In countries where the shooting of wildlife at night is lawful and considered acceptable by society (see Putman et al. 2011a), thermal imagers offer the clear advantage of detecting animals while the observer remains concealed by darkness. However, even in more restrictive countries such as the UK, thermal imagers offer tactical advantages over binoculars. We have demonstrated that during twilight, when deer can lawfully be shot, the number of deer and roe deer groups detected was significantly higher using the thermal imager. In a management context, this could translate as more shooting opportunities per day, or a higher probability of at least one successful shooting opportunity per day. While it is illegal to use thermal imaging telescopic rifle sights to shoot deer in the UK, a hand-held thermal imager can lawfully be used at any time of the day or night. It is thus conceivable that thermal surveillance of land for deer during the hours immediately before they can lawfully be shot could inform the deer manager on whether they should remain in position to await twilight or should move to a different location where deer are detected. Either way, thermal imagers offer significant potential for improving the culling efficiency of deer populations, at a time when their distributions and abundances (Mathews et al. 2018) and hence probably their impacts too (Putman et al. 2011b) have never been greater.

Acknowledgements We thank Tim Kohler, Natural England for permission to study on Thorne Moors, the Deer Initiative for loaning the thermal imager and Will Mayes for mapping guidance.

\section{Compliance with ethical standards}

All procedures were performed in accordance with the ethical standards of the University of Hull. Ethical Review reference U151.
Open Access This article is distributed under the terms of the Creative Commons Attribution 4.0 International License (http:// creativecommons.org/licenses/by/4.0/), which permits unrestricted use, distribution, and reproduction in any medium, provided you give appropriate credit to the original author(s) and the source, provide a link to the Creative Commons license, and indicate if changes were made.

\section{References}

Allison NL, Destefano S (2006) Equipment and techniques for nocturnal wildlife studies. Wildl Soc Bull 34(4):1036-1044

Bates D, Maechler M, Bolker B, Walker S (2014) lme4: linear mixedeffects models using Eigen and S4. R Package Version 1, pp 1-23

Beier P, McCullough DR (1990) Factors influencing white-tailed deer activity patterns and habitat use. Wildl Monogr 109(1):3-51

Benhaiem S, Delon M, Lourtet B, Cargnelutti B, Aulagnier S, Hewison AJM, Morellet N, Verheyden H (2008) Hunting increases vigilance levels in roe deer and modifies feeding site selection. Anim Behav 76(3):611-618

Field SA, O'Connor PJ, Tyre AJ, Possingham HP (2007) Making monitoring meaningful. Austral Ecol 32(5):485-491

Focardi S, De Marinis AM, Rizzotto M, Pucci A (2001) Comparative evaluation of thermal infrared imaging and spotlighting to survey wildlife. Wildl Soc Bull 29(1):133-139

Focardi S, Isotti R, Tinelli A (2002) Line transect estimates of ungulate populations in a Mediterranean forest. J Wildl Manag 66(1):48-58

Fragoso JM, Levi T, Oliveira LF, Luzar JB, Overman H, Read JM, Silvius KM (2016) Line transect surveys underdetect terrestrial mammals: implications for the sustainability of subsistence hunting. PloS One 11(4):e0152659

Gill RMA, Thomas ML, Stocker D (1997) The use of portable thermal imaging for estimating deer population density in forest habitats. J Appl Ecol 34(5):1273-1286

Harrison XA, Donaldson L, Correa-Cano ME, Evans J, Fisher DN, Goodwin C, Robinson BS, Hodgson DJ, Inger R (2018) A brief introduction to mixed effects modelling and multi-model inference in ecology. PeerJ 6:e4794. https://doi.org/10.7717/peerj.4794

Hewison AJM, Vincent JP, Joachim J, Angibault JM, Cargnelutti B, Cibien C (2001) The effects of woodland fragmentation and human activity on roe deer distribution in agricultural landscapes. Can J Zool 79(4):679-689

Horns JJ, Adler FR, Șekercioğlu ÇH (2018) Using opportunistic citizen science data to estimate avian population trends. Biol Conserv 221: $151-159$

Jiang G, Zhang M, Ma J (2008) Habitat use and separation between red deer (Cervus elaphus xanthopygus) and roe deer (Capreolus pygargus bedfordi) in relation to human disturbance in the Wandashan Mountains, northeastern China. Wildl Biol 14(1):92100

Legg CJ, Nagy L (2006) Why most conservation monitoring is, but need not be, a waste of time. J Environ Manag 78(2):194-199

MacKenzie DI, Nichols JD, Lachman GB, Droege S, Royle JA, Langtimm CA (2002) Estimating site occupancy rates when detection probabilities are less than one. Ecology 83(8):2248-2255

Massimino D, Harris SJ, Gillings S (2018) Evaluating spatiotemporal trends in terrestrial mammal abundance using data collected during bird surveys. Biol Conserv 226:153-167

Mathews F, Kubasiewicz LM, Gurnell J, Harrower CA, McDonald RA, Shore RF (2018) A review of the population and conservation status of British mammals. Natural England, Peterborough 
Meng X, Yang Q, Feng Z, Xia L, Wang P, Jiang Y, Bai Z, Li G (2002) Preliminary studies on active patterns during summer, autumn and winter seasons in captive alpine musk deer. Acta Theriol Sin 22(2): 87-97

Mitchell B, Staines BW, Welch D (1977) Ecology of red deer. Institute of Terrestrial Ecology, Cambridge

Nichols JD (2019) Confronting uncertainty: contributions of the wildlife profession to the broader scientific community. J Wildl Manag 83: 519-533. https://doi.org/10.1002/jwmg.21630

Petrovan SO, Ward AI, Wheeler P (2011) Detectability counts when assessing populations for biodiversity targets. PloS One 6(9):e24206

Putman RJ, Moore NP (1998) Impact of deer in lowland Britain on agriculture, forestry and conservation habitats. Mammal Rev 28(4):141-164

Putman R, Apollonio M, Andersen R (2011a) Ungulate management in Europe. Problems and practices. Cambridge University Press, Cambridge

Putman R, Langbein J, Green P, Watson P (2011b) Identifying threshold densities for wild deer in the UK above which negative impacts may occur. Mammal Rev 41(3):175-196

R Core Team (2018) R: A language and environment for statistical computing. R Foundation for Statistical Computing, Vienna, Austria. https://www.R-project.org/
Smart JC, Ward AI, White PCL (2004) Monitoring woodland deer populations in the UK: an imprecise science. Mammal Rev 34(1-2):99114

Trenkel VM, Buckland ST, McLean C, Elston DA (1997) Evaluation of aerial line transect methodology for estimating red deer (Cervus elaphus) abundance in Scotland. J Environ Manag 50(1):39-50

Vincent JP, Gaillard JM, Bideau E (1991) Kilometric index as biological indicator for monitoring forest roe deer populations. Acta Theriol 36(3-4):315-328

Wäber K, Spencer J, Dolman PM (2013) Achieving landscape-scale deer management for biodiversity conservation: the need to consider sources and sinks. J Wildl Manag 77(4):726-736

Ward AI (2005) Expanding ranges of wild and feral deer in Great Britain. Mammal Rev 35(2):165-173

Zuur A, Ieno EN, Smith GM (2007) Analyzing ecological data. Springer Science \& Business Media

Publisher's note Springer Nature remains neutral with regard to jurisdictional claims in published maps and institutional affiliations. 